\title{
Article
}

\section{Comparison of toxic product yields of burning cables in bench and large-scale experiments}

Hull, T Richard, Lebek, K., Pezzani, M. and Messa, S.

Available at http://clok.uclan.ac.uk/1065/

Hull, T Richard ORCID: 0000-0002-7970-4208, Lebek, K., Pezzani, M. and Messa, S. (2008) Comparison of toxic product yields of burning cables in bench and large-scale experiments. Fire Safety journal, 43 (2). pp. 140-150. ISSN 0379-7112

It is advisable to refer to the publisher's version if you intend to cite from the work. http://dx.doi.org/10.1016/j.firesaf.2007.06.004

For more information about UCLan's research in this area go to http://www.uclan.ac.uk/researchgroups/ and search for <name of research Group>.

For information about Research generally at UCLan please go to http://www.uclan.ac.uk/research/

All outputs in CLoK are protected by Intellectual Property Rights law, including Copyright law. Copyright, IPR and Moral Rights for the works on this site are retained by the individual authors and/or other copyright owners. Terms and conditions for use of this material are defined in the policies page.

\section{CLoK}

Central Lancashire online Knowledge www.clok.uclan.ac.uk

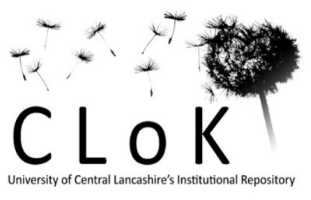


Fire Safety Journal, 43 (2), pp. 140-150, 2008. ISSN 0379-7112

\title{
Comparison of toxic product yields of burning cables in bench and large scale experiments
}

\author{
T Richard Hull ${ }^{1}$, Krzysztof Lebek ${ }^{1}$, Maddalena Pezzani ${ }^{2}$ and Silvio Messa ${ }^{2}$, \\ 1. Fire Materials Laboratories, CMRI, \\ University of Bolton, \\ Deane Road \\ Bolton BL3 5AB
}

2. L.S. Fire Laboratories

Via Garibaldi 28/A

22070 Montano Lucino (Como)

Italy

\begin{abstract}
Toxic product yields from five commercial cables obtained from a steady state tube furnace method (IEC 60695-7-50, the Purser furnace,) are compared with results from a large scale test, which uses the physical fire model in the proposed prEN50399-2-2 test, with the addition of effluent gas analysis, using Fourier transform infrared (FTIR), and for further comparison, a static tube furnace method (NF X 70-100). This work represents one of the first attempts to establish a relationship between bench- and large-scale toxic product yields for burning cables. This is difficult because the cables have been formulated for low flammability, and do not, therefore burn consistently. The tube furnace burns the cable completely, whereas the large scale test effluent is the result of a combination of flame spread and toxic product yields, both of which are fire scenario dependant. There is significant differentiation between cable types based on composition, and arising because only a portion of the cables burn in the large scale test, accompanied by possible decomposition of hydrate sheaths. The fire stage of the large scale test appears to have been replicated in an appropriate manner, given the correspondence of the $\mathrm{CO}_{2} / \mathrm{CO}$ ratios. The yields of $\mathrm{CO}_{2}, \mathrm{CO}, \mathrm{HCl}$ and smoke show reasonable agreement, given the differences in extent of burning, and the accuracy of the mass loss data available for the large scale test. The yields and extent of burning have been combined to demonstrate the estimation of toxic hazard for a particular fire scenario based around the large scale test, which shows only marginal sensitivity to the differences in toxic product yield between the steady state tube furnace and the large scale test.
\end{abstract}

KEYWORDS: Fire toxicity, cables, PVC, EVA, ATH, polyolefin, carbon monoxide 


\section{LIST OF ABBREVIATIONS}

ATH

EHC

EVA

FPA

FED

FTIR

$\mathrm{LC}_{50}$

PVC

SSTF

SSTP Cat 7
Aluminium hydroxide $\left(\mathrm{Al}(\mathrm{OH})_{3}\right)$

Effective heat of combustion

Ethylene-vinyl acetate copolymer

Fire propagation apparatus

Fractional effective dose

Fourier transform infrared

Lethal concentration to $50 \%$ of population

Polyvinyl chloride

Steady state tube furnace

Screened-screened twisted pair (a doubly screened data

cable meeting the requirements of ISO/IEC 11801 class F)

\section{Introduction}

The majority of deaths in fires result from inhalation of toxic gases ${ }^{1}$. The yield of toxic gases is dependent on both the fire conditions and the material formulation ${ }^{2}$. Electric cables frequently present a fire risk because of the remote location of their installation and the increasing quantities of installed cables. This risk translates into a significant hazard because cables are frequently installed in hidden channels which may breach the normal fire enclosures within a building, if not properly fire-stopped. Thus a cable fire could develop unnoticed, and then spread from compartment to compartment.

Fire (or smoke) toxicity has assumed a greater importance, particularly for high risk applications. Estimation of the yields of toxic products within fire effluents is increasingly being recognised as a major factor in the assessment of fire hazard. Additionally, as prescriptive standards of fire behaviour for product acceptance are replaced by holistic performance based fire codes allowing a wider range of materials to be selected, architects can now specify that new buildings require assessment by fire safety engineers in terms of flame spread and yield and distribution of toxic fire gases within the time required to escape ${ }^{3}$. 


\section{Fire Types}

The yields of most toxic products are highly dependant on the fire conditions. As an enclosure fire develops, the temperature increases and oxygen concentration decreases. This has been set out as series of characteristic fire stages ${ }^{4}$, from smouldering to post-flashover, providing guidance as to how to identify fire conditions from their $\mathrm{CO}_{2} / \mathrm{CO}$ or equivalence ratio. This implies that if the same $\mathrm{CO}_{2} / \mathrm{CO}$ ratio is obtained in two apparatuses, then the fire condition is also the same. However, as noted in the ISO standard, the presence of halogens will affect the $\mathrm{CO}_{2} / \mathrm{CO}$ ratio, so for PVC cables it cannot be used directly to characterise a fire stage, because their values would be much lower, $\mathrm{CO}_{2} / \mathrm{CO}$ ratios can still be used to compare the fire conditions of halogen containing materials in different apparatuses. Table 1 shows the three most important fire stages, which have been investigated in this work.

Table 1 ISO classification of fire stages, based on ISO $19706^{4}$.

\begin{tabular}{|c|c|c|c|c|c|c|c|}
\hline \multirow[t]{2}{*}{ Fire Stage } & \multicolumn{2}{|c|}{ Max Temp $/{ }^{\circ} \mathrm{C}$} & \multicolumn{2}{|c|}{ Oxygen \% } & \multirow{2}{*}{$\begin{array}{c}\text { Equivalence } \\
\text { ratio } \\
\phi\end{array}$} & \multirow{2}{*}{$\frac{\mathrm{V}_{\mathrm{CO}_{2}}}{\mathrm{~V}_{\mathrm{CO}}}$} & \multirow{2}{*}{$\begin{array}{c}\text { Combustion } \\
\text { Efficiency } \\
\%\end{array}$} \\
\hline & Fuel & Smoke & To fire & $\begin{array}{c}\text { From } \\
\text { fire }\end{array}$ & & & \\
\hline $\begin{array}{c}\text { 1b Oxidative } \\
\text { pyrolysis }\end{array}$ & $300-600$ & & 20 & 20 & & & \\
\hline $\begin{array}{l}2 \text { Well ventilated } \\
\text { flaming }\end{array}$ & $350-650$ & $50-500$ & $\begin{array}{l}20 \\
\sim\end{array}$ & $0-20$ & $<1$ & $>20$ & $>95$ \\
\hline $\begin{array}{l}\text { 3b Underventilated } \\
\text { Flaming - Post } \\
\text { flashover }\end{array}$ & $350-650$ & $>600$ & $<15$ & $<5$ & $>1$ & $2.5-10$ & $70-90$ \\
\hline
\end{tabular}

This work describes the comparison of two bench-scale physical fire models with a well-ventilated large-scale fire scenario. However, it is important to note that although most large-scale fire tests are well-ventilated, if a real fire is allowed to grow, transition through the different fire stages occurs, and for most materials the highest yields of the most toxic species, such as $\mathrm{CO}$, are found under oxygen-depleted conditions. These are the conditions where the heat flux is sufficient to drive the decomposition and pyrolysis processes forward, but there is insufficient oxygen to allow the combustion reactions to go to completion. The factors controlling a material's fire gas toxicity are generally poorly understood, but have been shown to be somewhat independent of material ${ }^{5}$ for many common aliphatic polymers composed of carbon, hydrogen and oxygen, but highly dependent on fire conditions. The range of different full-scale fire scenarios, and the difficulties in predicting large scale behaviour on a small-scale, has resulted in the determination of toxic product yields being neglected in the development of fire retarded materials.

Attempts to determine the toxic product yields on a bench scale from burning materials and products rely on replication of the appropriate fire condition. The different approaches have been described ${ }^{6}$. Typically the bench-scale apparatuses fall into three types, well-ventilated (only representing the least toxic fire stage), closed box (integrating all the fire stages into one result) and flow-through (allowing separation of fire stages through control of ventilation). The closed box tests, such as the NBS Cup furnace (Pott's Pot), the Radiant Furnace test ASTM E1678, and tests using the NBS Smoke Chamber (ASTM E662 and ISO 5659-2) give a complete 
product yield of burning from well-ventilated right through to fully vitiated, but without giving any indication of how the yield varies with fire condition. Sampling from such devices during burning is possible but this may either deplete the fire gases if they are not returned to the box, or may change product, for example by filtration prior to analysis, if they are to be recirculated. The French railway test (NF X 70$100)$, is a small scale ( 1g) decomposition apparatus where the products are analysed and a toxicity index is generated, but there is no control over the ventilation for a particular decomposition rate. The other tube methods such as the fire propagation apparatus (FPA) (ASTM E2058) developed by FM Global, the DIN 53436 and the steady state tube furnace ${ }^{7}$ (SSTF) (IEC 60695-7-50) all allow the possibility of controlling the fire conditions during burning. The FPA allows the rate of burning to vary under a constant heat flux, similar to the cone, but with much improved control of ventilation. In contrast, the DIN 53436 and the IEC 60695-7-50force combustion by feeding the sample into a heated zone of increasing heat flux at a fixed rate, thus replicating steady state burning. As the sample moves into the furnace, lying in an 80 $\mathrm{cm}$ long silica boat, it experiences increasing radiant flux intensity until it ignites, then the flame spreads backwards slightly, to a cooler part of the furnace. At low oxygen concentrations, or for fire retarded materials, where ignition is more difficult, the sample reaches a hotter part of the furnace before igniting, and again, the flame will stabilise itself, as it spreads a little way back up the tube. Thus flammable and highly fire retarded materials are forced to burn at the same rate.

The aim of this work is to assess the degree of correspondence between the benchscale steady state tube furnace data on toxic product yields from burning cables of low flammability with those from a well-ventilated large scale test. The steady state tube furnace $^{7}$ is the IEC 60695-7-50:2002 (Purser furnace) which allows the rates of burning and ventilation to be controlled. The large scale test is prEN50399-2-2, which uses the IEC 60332-3 test chamber, chosen by the regulators for cable testing, but with the addition of gas analysis by FTIR. The data from a simple static tube furnace method (NF X 70-100) are also included in the comparison, where appropriate data was available.

The problem of relating real-scale fire behaviour to bench scale tests revolves around replication of the fire conditions. These include temperature, residence time in the fire plume, radiation from the flame to the material, ventilation to the fire plume and reactions occurring outside the fire plume (for example in a reactive hot layer). Crucially, these dictate both the rate and extent of burning. Carbon monoxide (CO) is a major toxicant, often reported to be responsible for most fire fatalities ${ }^{8}$, although there is mounting evidence to show that this is not always the case ${ }^{9}$. The yield of CO is highly dependent on fire conditions. However, high CO yields in fires may result from four separate conditions, insufficient heat, insufficient oxygen, chemical quenching of the fire plume and the presence of more stable fuel molecules, such as aromatics in the flame zone. Thus high concentrations of CO appear early on, during smouldering and up to ignition, and much later, when an enclosed fire is so large that it becomes starved of oxygen. In addition, materials such as $\mathrm{PVC}^{10}$ and polystyrene ${ }^{5}$ also give higher yields of $\mathrm{CO}$ in well-ventilated burning. The sensitivity to fire conditions of other toxicants is less well characterised, although the yield of HCN and many irritant gases such as hydrocarbons, generally increase with decreasing ventilation, following $\mathrm{CO}$, while $\mathrm{HCl}$ and $\mathrm{HBr}$ yields are largely independent of ventilation conditions. 


\section{Fire Toxicity and Fractional Effective Dose (FED)}

The criteria used for assessing smoke toxicity from chemical analysis of fire effluents and how it must be measured have been defined ${ }^{11}$. The methodology is based on the results of experiments using exposure of rats to the common fire gases, both singly and in combinations. The general approach is to assume additive behaviour of individual toxicants, and to express the concentration of each as its fraction of the lethal concentration for $50 \%$ of the population $\left(\mathrm{LC}_{50}\right.$ ) over a 30 minute exposure time, within a 14 day post-exposure period. Thus an FED equal to one predicts that the fire gas will be lethal to $50 \%$ of a laboratory rat population.

$$
\mathrm{FED}=\frac{m[\mathrm{CO}]}{\left[\mathrm{CO}_{2}\right]-b}+\frac{21-\left[\mathrm{O}_{2}\right]}{21-\mathrm{LC}_{50, \mathrm{O}_{2}}}+\frac{[\mathrm{HCN}]}{\mathrm{LC}_{50, \mathrm{HCN}}}+\frac{[\mathrm{HCl}]}{\mathrm{LC}_{50, \mathrm{HCl}}}+\frac{[\text { Acrolein }]}{\mathrm{LC}_{50, \text { Acrolein }}}+\frac{[\text { Formaldehyde }]}{\mathrm{LC}_{50, \text { Formaldehyde }}}+\ldots .
$$

\section{Equation 1}

Table 2 30-min $\mathrm{LC}_{50}$ values ${ }^{11}$ used in this study

\begin{tabular}{|l|l|}
\hline Fire effluent gas & ppm \\
\hline $\mathrm{CO}$ & 5700 \\
\hline $\mathrm{HCl}$ & 3800 \\
\hline Acrolein & 150 \\
\hline Formaldehyde & 750 \\
\hline
\end{tabular}

Equation 1, referred to as the N-Gas model, uses this approach, and table 2 shows the values specified in ISO 13344. However, in the first term the effect of the CO is enhanced by the increase in respiration rate caused by high concentrations of $\mathrm{CO}_{2}$, (expressed as a step function with one value of constants $m$ and $b$ for $\mathrm{CO}_{2}$ concentrations below 5\% and another for those above 5\%).

\section{Experimental}

\section{Bench-scale methods (IEC 60695-7-50 and NF X 70-100)}

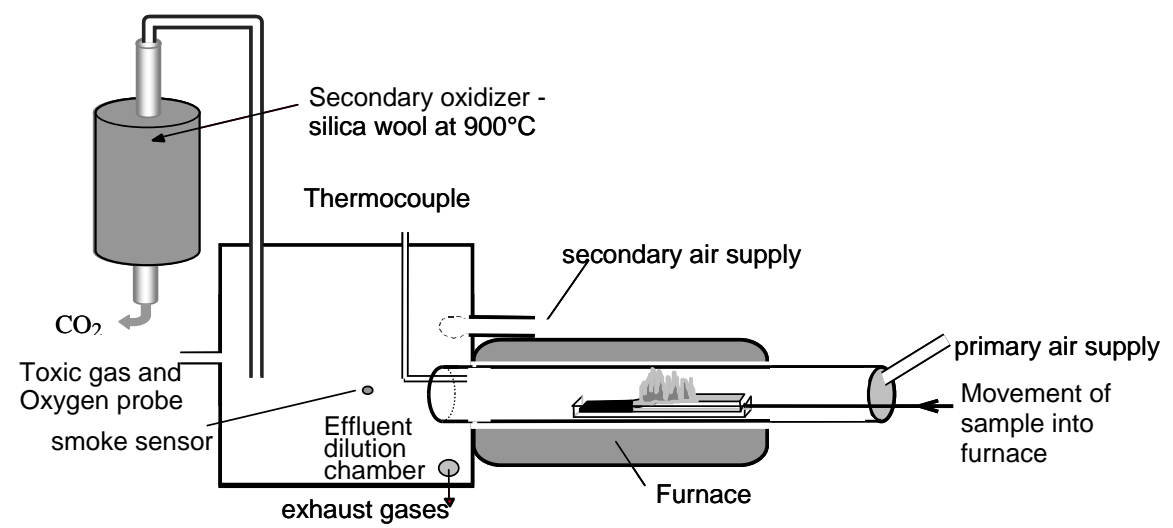

Figure 1 The steady state tube furnace apparatus ${ }^{7}$ (Purser furnace) showing the addition of a secondary oxidiser. 
The standard IEC 60695-7-50:2002, describes a method capable of measuring the toxic product yields from burning materials at different fire stages in the steady state tube furnace. The apparatus is illustrated in Fig. 1. In real-scale fires, growth will continue until it is limited by the oxygen supply. This may increase the toxic product yield by ten times or more. In bench-scale tests, the fuel-air ratio allows the fire stage to be defined for flaming combustion. However, since typical polymeric cable materials may contain a variety of undisclosed components with up to $70 \%$ inorganic fillers, it is not always possible to estimate the fuel content, and hence the stoichiometric (chemical) oxygen requirement of the material. IEC 60695-7-50 defines extremes of under and over-ventilation for the steady state tube furnace, corresponding to the characteristic fire stages ${ }^{4}$. These conditions are summarised in table 1.

Table 3. Furnace conditions corresponding to characteristic stages of burning behaviour used in IEC 60695-7-50.

\begin{tabular}{|ll|c|c|}
\hline \multicolumn{2}{|l|}{ Fire Stage } & $\begin{array}{l}\text { Furnace } \\
\text { Temp. } /\left({ }^{\circ} \mathrm{C}\right)\end{array}$ & $\begin{array}{l}\text { Primary air } \\
\text { flow } /(1 / \mathrm{min})\end{array}$ \\
\hline 1b & Oxidative pyrolysis & 350 & 1.1 \\
\hline 2 & Well ventilated flaming & 650 & 22.6 \\
\hline 3b & Under-ventilated flaming - post flashover & 825 & 2.7 \\
\hline
\end{tabular}

The NF X 70-100 test, shown in Figure 2 was originally devised for fire toxicity assessment by SNCF (and known as the French Railway test). It uses a smaller diameter tube furnace, set to $800^{\circ} \mathrm{C}$ in this work, with a 1 gram sample placed in the middle of the furnace under 2 litres $\min ^{-1}$ of flowing air, for 20 minutes. The effluent is collected and analysed for toxic and irritant species, using FTIR. There was no facility to observe whether flaming combustion had occurred.

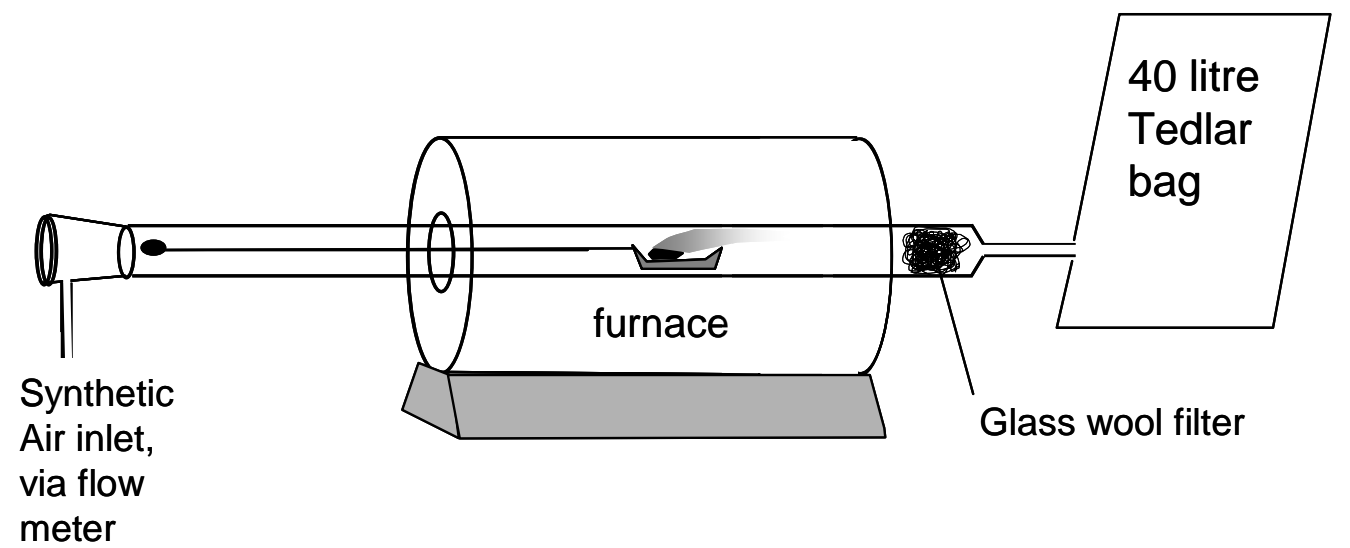

Figure 2 The NF X 70-100 apparatus set up 


\section{Large Scale Test Apparatus}

The apparatus is based on a modified bunched vertical wire test (IEC 60332-3) using the cabin set up, and the method follows prEN50399-2-2.

The test chamber has a rectangular base of $205 \mathrm{~cm}$ by $110 \mathrm{~cm}$, and a height of $410 \mathrm{~cm}$. Air is pumped in at 133 litres s$^{-1}$ through a $25 \mathrm{~cm}$ diameter duct into a perforated base plate $(80 \mathrm{~cm} \times 40 \mathrm{~cm})$. The main burner is situated $60 \mathrm{~cm}$ above the base plate, set to deliver $20 \pm 2 \mathrm{~kW}$. The cables are mounted on a vertical steel ladder facing this burner, as shown in Figure 3 . $200 \mathrm{~cm}$ above the base plate, away from the cables in the centre of the test chamber, is a secondary burner. The exhaust gases are collected in a hood, which consists of a cube above a square conical section. The cube is connected to an exhaust duct, about $600 \mathrm{~cm}$ long, leading to the measurement probes for gas analysis. At the top of the test chamber an additional air supply of 167 litres $\mathrm{s}^{-1}$ is introduced into the exhaust duct to ensure sufficient flow in the $25 \mathrm{~cm}$ diameter duct to reach an appropriate Reynolds number to ensure adequate mixing of the sample gases. The data was calculated back to a flow of 133 litres s ${ }^{-1}$. The point of measurement of smoke opacity is at about $610 \mathrm{~cm}$ from beginning of duct. The pressure in the duct (bi-directional) is measured at $650 \mathrm{~cm}$, sampling of gases for FTIR analysis at $670 \mathrm{~cm}$, and the determination of oxygen concentration is carried out at $680 \mathrm{~cm}$ from the beginning of duct. Both burners operate for the full 20 minute duration of the test. At the end of the test period, for all the cables reported here, the only contribution to the heat release came from the propane burner.

In this work, data obtained from burning cables of length $350 \mathrm{~cm}$, on a vertical cable ladder under well-ventilated conditions are compared to product yields for a wellventilated fire using 22.6 litres of air per gram of material at $650^{\circ} \mathrm{C}$, and where appropriate compared to data for under-ventilated combustion using 2.7 litres of air per gram of material at $825^{\circ} \mathrm{C}$, and data from the NFX-70-100 test at $800^{\circ} \mathrm{C}$. 

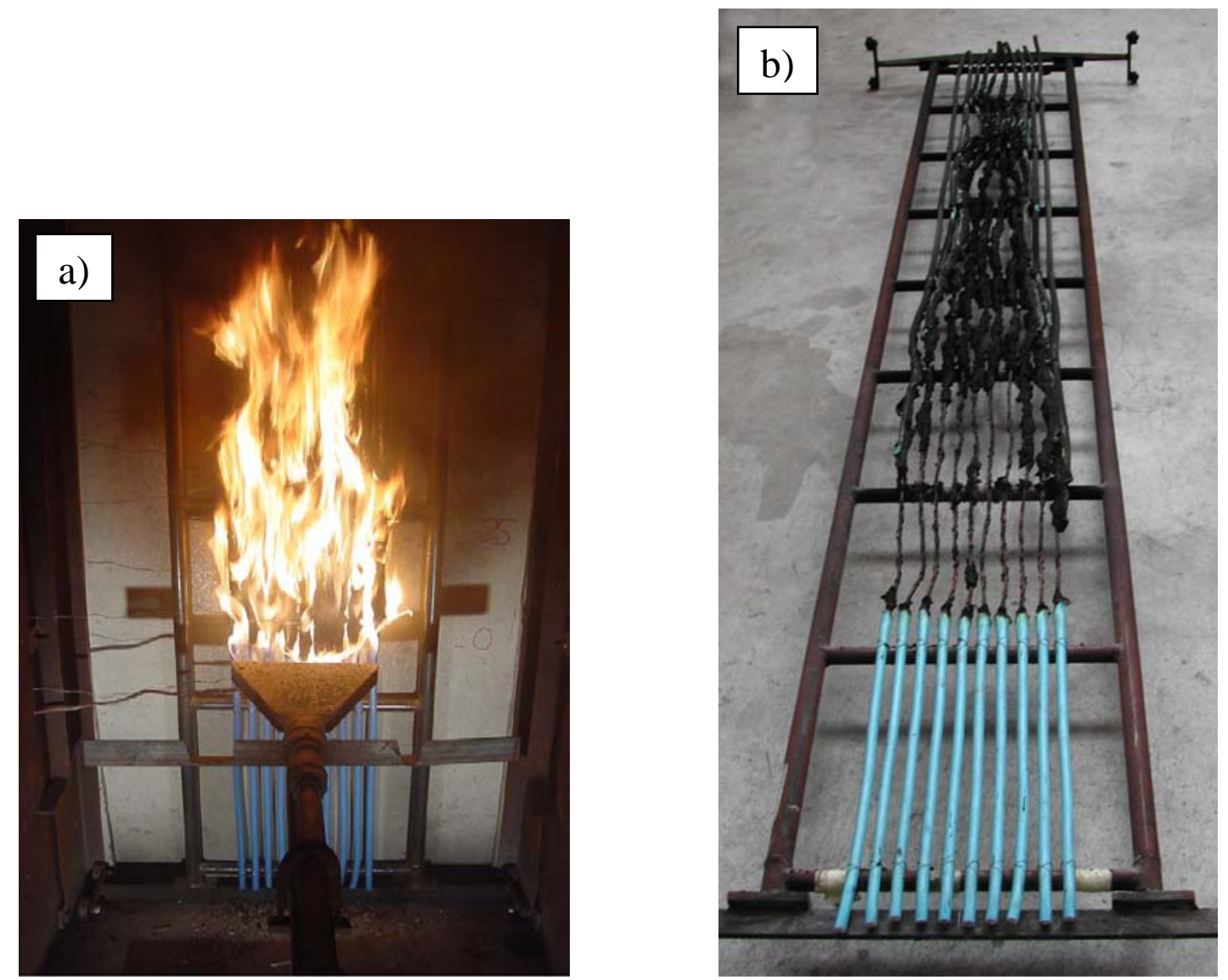

Figure 3 a) The fire model in action, and b) a cable ladder after burning

\section{Materials}

Five cables were investigated, as shown in Table 4 . The cables for testing in the steady state tube furnace were chosen from those already tested in the large scale test with a diameter below $15 \mathrm{~mm}$, in order to ensure adequate ventilation in the $\sim 50 \mathrm{~mm}$ diameter furnace tube of the SSTF.

Table 4 Cable identification and description

\begin{tabular}{|l|l|l|l|l|}
\hline Cable & Designation & Conductors & $\begin{array}{l}\text { Cable } \\
\text { Compound } \\
\text { description }\end{array}$ & $\begin{array}{l}\text { Cable Construction (from outer to } \\
\text { conductor) }\end{array}$ \\
\hline Energy & RZ1-K & $3 \times 1.5 \mathrm{~mm}^{2}$ & LSZH & Sheath - Insulation \\
\hline Energy & RV-K & $3 \times 1.5 \mathrm{~mm}^{2}$ & PVC & Sheath - Insulation \\
\hline Energy & NYM $^{*}$ & $3 \times 1.5 \mathrm{~mm}^{2}$ & PVC & Sheath - Bedding - Insulation \\
\hline Energy & NO7V-K & $1 \times 2.5 \mathrm{~mm}^{2}$ & PVC & Insulation \\
\hline Data & SSTP Cat 7 & 4 Pair23AWG & LSZH & $\begin{array}{l}\text { Sheath - woven wire screen - foil } \\
\text { screen - insulation }\end{array}$ \\
\hline
\end{tabular}

* Two different cables both meeting the DIN NYM specification were tested, one in the steady state tube furnace and a different one in the large scale test and the NFX 70-100. The results are included for comparison purposes. 
Since most of the cables are protected by a fire retarded sheath which surrounds more flammable insulation material, the relevant scenario would burn the cables whole. Under certain conditions, in the large-scale test, the fire retarded sheath would reduce the availability of combustible material. In the steady state tube furnace, whole lengths of cable were used and the boat speed adjusted to give a feed rate of $1 \mathrm{~g} \mathrm{~min}^{-1}$. In the NFX-70-100 test each cable component, sheathing, bedding and insulation were tested separately after the conductors had been removed, and the results presented as weighted averages.

Most cable formulations tend to follow similar trends. For example PVC cable sheathing and insulation contains approximately equal masses of PVC polymer, plasticizer (often di-iso octyl phthalate) and chalk. The bedding often contains up to $80 \%$ chalk, which can trap some of the hydrogen chloride gas $(\mathrm{HCl})$. The insulation of low smoke zero-halogen (LSZH) formulations generally uses polyethylene for data cables and cross-linked polyethylene for energy cables, and is thus the main flammable component. A typical fire retarded sheath may consist of 30-35\% ethylene-vinyl acetate copolymer, and 65-70\% aluminium or magnesium hydroxide $\left(\mathrm{Al}(\mathrm{OH})_{3}\right.$ referred to as $\mathrm{ATH}$, or $\left.\mathrm{Mg}(\mathrm{OH})_{2}\right)$, which will decompose endothermically to release water leaving alumina, $\mathrm{Al}_{2} \mathrm{O}_{3}$ or magnesia, MgO. Earlier work has shown that the presence of alumina can promote char oxidation, influencing the yields of carbon monoxide ${ }^{12}$.

\section{Results and Discussion}

\section{Extent of Burning}

In the well-ventilated tube furnace all the cable passed through the furnace at $650^{\circ} \mathrm{C}$, ignited and burnt along their whole length, with all residues being retained in the boat, giving a fairly uniform mass loss for the different cables. In the large scale test, burning is often incomplete. The photograph (Figure 3b) shows a typical cable ladder after burning. It is clear that the bottom section is unburnt, near the burner the cable is completely burnt and most of the residue has fallen to the floor, above it there is a large triangular area of partial fire damage, with smaller unburnt sections in the top corners. In this test, the amounts of toxic products depend both on the cable flammability and its burning behaviour (itself dependent on how it is mounted etc.) and on the toxic product yield. As smaller proportions of the total mass of cable were burned, the amounts of toxic products will be lower for the same length of cable, but the yields (if expressed on a mass-loss basis) should be comparable, provided that most of the cable is either burnt completely, or not at all, and that the product yields are not too sensitive to differences in fire conditions between the tests.

\section{Mass Loss}

The mass losses shown in Table 5 represent losses for the non-metallic component of the cable. In this work it is assumed that only loss of polymer compound (not copper, but including the metallised polymer screen of the SSTP cable) will result in mass loss, and all data are presented on a mass loss basis. 
Table 5 Mass Loss of compound for each cable for the two scales of test

\begin{tabular}{|l|r|r|r|r|r|}
\hline & RZ1-K & RV-K & NYM & NO7V-K & $\begin{array}{c}\text { SSTP } \\
\text { Cat 7 }\end{array}$ \\
\hline Large Scale Mass loss \% & 47.0 & 57.6 & 29.3 & 15.2 & 34.6 \\
\hline Large Scale Mass loss corrected for loss of residue \% & 29.5 & 41.5 & 29.3 & 15.2 & 34.6 \\
\hline Tube furnace mass loss at $650^{\circ} \mathrm{C}$ well-ventilated \% & 62.8 & 66.6 & 56.6 & 65.1 & 69.7 \\
\hline Tube furnace mass loss at $85^{\circ} \mathrm{C}$ under-ventilated \% & 60.7 & 72.0 & 59.1 & 66.0 & 65.0 \\
\hline $\begin{array}{l}\text { Proportion of completely burnt cable in large scale } \\
\text { test by mass \% }\end{array}$ & 47.0 & 57.6 & 49.6 & 23.1 & 49.6 \\
\hline Burn damage area \% & 59 & 88 & 66 & 29 & 59 \\
\hline Proportion of partly burnt cable \% & 12 & 30 & 17 & 6 & 9 \\
\hline
\end{tabular}

Photographs of the burnt cable show the loss of "char", believed to be predominantly inorganic residue, from the cable ladder from two of the cables (RZ1-K and RV-K), similar to that shown just above the unburnt cable in figure $3 \mathrm{~b}$. Since the residues in the tube furnace experiments were retained in the sample boat, correction for the loss of residue has been made to the mass loss which is used to normalise the large scale data (for THR, $\mathrm{CO}_{2}, \mathrm{CO}$ and $\mathrm{HCl}$ yield, Mass Optical Density and FED). This is shown in table 3. The "proportion of completely burnt cable in the large-scale test" in table 3 is the ratio of the corrected mass loss in the large scale test to the larger of the two mass losses in the steady state tube furnace (which is assumed to have burnt completely). This is compared to the "burn damage area" for each of the cables in the large scale test, which was estimated from photographs. Finally, the difference between the visual estimation of burn damage area and the estimate based on mass loss is expressed as the "proportion of partly burnt cable". 


\section{Effective Heat of Combustion}

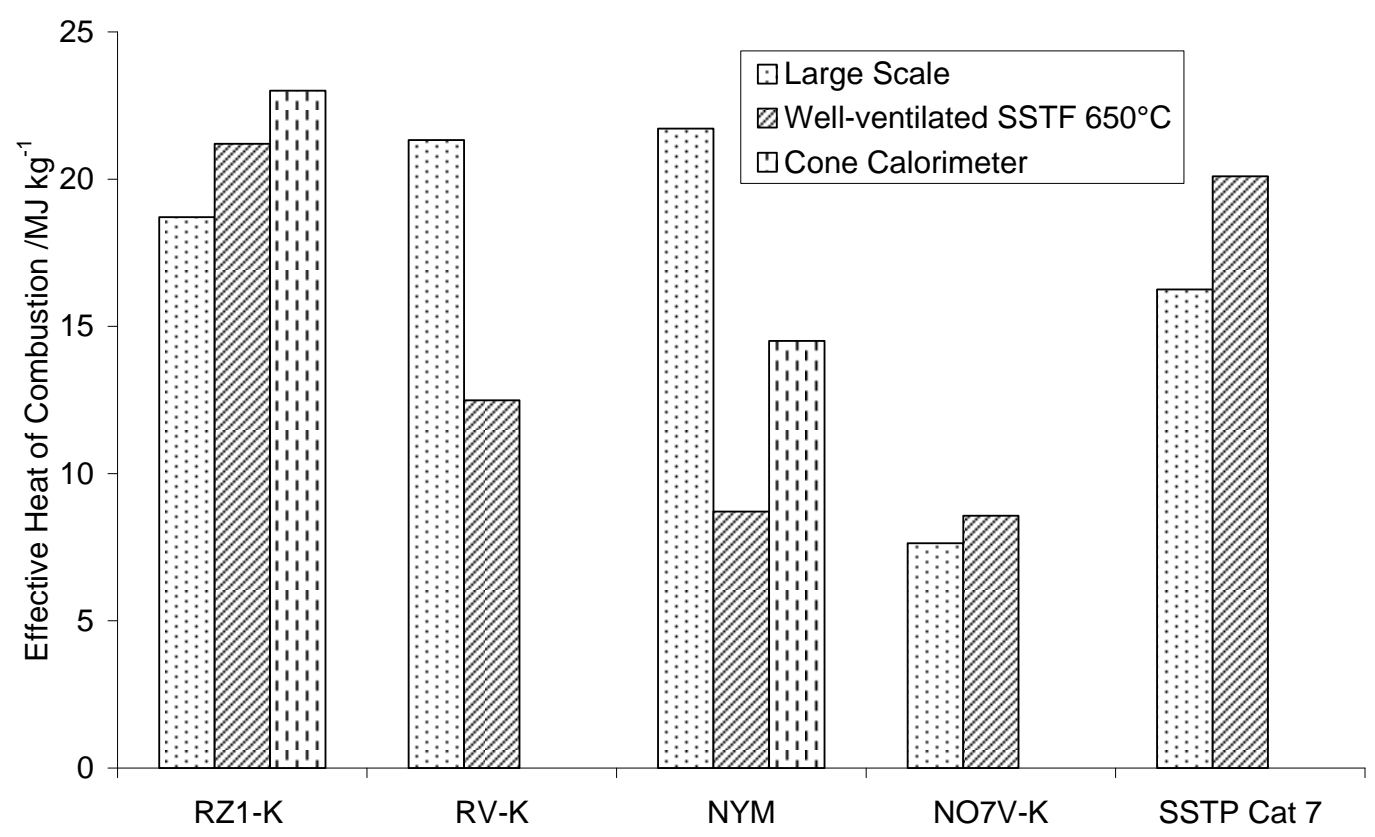

Figure 4 Effective Heat of Combustion compared for the different cables using the small and large scale fire models, on a mass loss basis.

Figure 4 shows the effective heat of combustion (EHC) from the steady state tube furnace measured by oxygen depletion calorimetry ( $1 \mathrm{~g} \mathrm{O}_{2}$ consumed corresponds to $13.1 \mathrm{~kJ}$ ) on a mass loss basis is compared to the total heat release from the large scale test (normalised to a mass loss basis, after subtraction of the contribution from the propane burner). The effective heats of combustion in the steady state tube furnace were calculated using Equation 2.

$\Delta H_{\text {comb }}=\left(x_{\mathrm{O}_{2} \text { ambient }}-x_{\mathrm{O}_{2} \text { chamber }}\right) \frac{\dot{V}_{\text {chamber }} M_{\mathrm{O}_{2}} f_{\text {mass loss }}}{V_{m} \dot{m}_{\text {cable }}} \times 13.1$

Equation 2

Where $x_{O_{2} \text { ambient }}$

$X_{\mathrm{O}_{2} \text { chamber }}$

$\dot{V}_{\text {chamber }}$

$M_{\mathrm{O}_{2}}$

$f_{\text {mass loss }}$

$V_{m}$

$\dot{m}_{\text {cable }}$ ambient mole fraction of oxygen

chamber mole fraction of oxygen

volume of gas flowing through chamber per minute

relative molecular mass of oxygen

the fraction of mass lost

the molar volume of gas at $298 \mathrm{~K}$

the mass of cable per minute to the furnace.

The effective heat of combustion is a function of the dynamics of the fire and the combustion efficiency, and there is relatively good agreement between the two experimental scenarios. In two cases corresponding data from the cone calorimeter is also available, showing good agreement with the steady state tube furnace. The slightly smaller values of effective heat of combustion in the large scale test for RZ1- 
K, NO7V-K and SSTP Cat 7 either fall within the limits of uncertainty, or suggest partial decomposition of the cable, while the surprisingly higher values in the large scale test for two of the PVC formulations suggests more complete burning (particularly char oxidation) of the burnt sections of the cable. In each case it is apparent that for low flammability cables, the effective heat of combustion is not a material property, but is highly dependent on scenario.

The EHC from other experiments conducted on the NYM cable under different ventilation conditions at $800^{\circ} \mathrm{C}$ are shown in table 6 using the equivalence ratio, $\phi$, defined in equation 3 .

$\phi=\frac{\text { actual fuel to air ratio }}{\text { stoichiometric fuel to air ratio }}$

Equation 3

Table 6 Effective heat of combustion for NYM cable as a function of equivalence ratio

\begin{tabular}{|c|c|}
\hline$\phi$ & $\begin{array}{c}\mathrm{EHC} / \\
\mathrm{MJ} \mathrm{kg}^{-1}\end{array}$ \\
\hline 0.13 & 9.3 \\
\hline 0.24 & 20.8 \\
\hline 0.50 & 22.0 \\
\hline 0.59 & 21.7 \\
\hline
\end{tabular}

This shows that in conditions of excessive over-ventilation $(\phi=0.13)$ a very low EHC of $9.3 \mathrm{MJ} \mathrm{kg}^{-1}$ is found, which is similar to the well-ventilated condition defined by IEC 60695-7-50 where a similarly low EHC is found (8.7 $\left.\mathrm{MJ} \mathrm{kg}^{-1}\right)$. As the equivalence ratio increases towards stoichiometric, so the EHC stabilises around $21 \mathrm{MJ} \mathrm{kg}^{-1}$, showing much better agreement with the value found in the large scale test. Thus the "well-ventilated flaming" condition, defined by IEC 60695-7-50, may not be appropriate to a typical well-ventilated fire scenario. In making comparisons with other published data on EHC from cables, it is important to distinguish between the more common method of reporting data on a mass-charge basis, and the method used here of reporting data on a mass-loss basis (to make meaningful comparisons with the large scale test). 


\section{$\mathrm{CO}_{2} / \mathrm{CO}$ ratio}

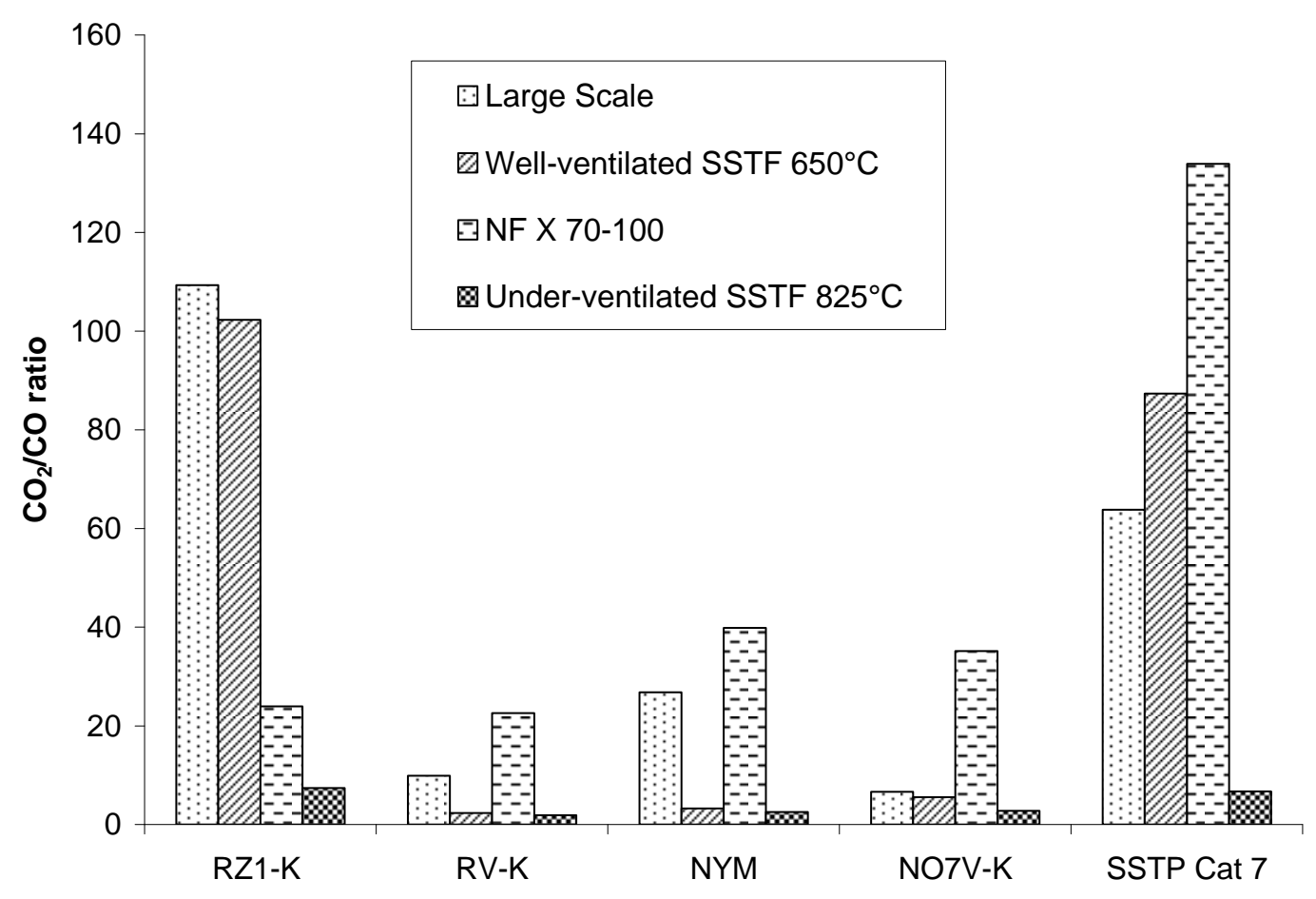

Figure $5 \mathrm{CO}_{2} / \mathrm{CO}$ ratio for each cable for different fire conditions

The $\mathrm{CO}_{2} / \mathrm{CO}$ ratio is used as an indicator of fire condition. The $\mathrm{CO}_{2} / \mathrm{CO}$ ratio for the different cables in the different test scenarios is shown in Figure 5, with typically well ventilated flaming for the RZ1-K and SSTP Cat 7 cables and characteristically lower values for the halogen containing RV-K, NYM and NO7V-K cables. The flame retardant action of halogens provide stable free radicals in the gas phase ${ }^{13}$, which reduce the concentration of highly reactive species such as $\mathrm{H}$ - and $\mathrm{OH}$. Both of these radicals are involved in the main heat release step of hydrocarbon combustion, the conversion of $\mathrm{CO}$ to $\mathrm{CO}_{2}$ (Equation 4).

$$
\mathrm{CO}+\mathrm{OH} \cdot \rightarrow \mathrm{CO}_{2}+\mathrm{H} \cdot
$$

\section{Equation 4}

This will reduce the $\mathrm{CO}_{2} / \mathrm{CO}$ ratio. There is consistent behaviour between the large scale and well-ventilated steady state tube furnace but less consistency between the static (NFX 70-100) and steady state tube furnace representing under-ventilated flaming. The greater differences for the NYM cable may result from differences between the two cable formulations, which both meet the NYM specification. There may be more efficient trapping of $\mathrm{HCl}$ by the chalk-filled bedding layer in the NYM cable used for the large scale and NF X 70-100 tests, favouring a shift towards higher $\mathrm{CO}_{2} / \mathrm{CO}$ ratios. 


\section{$\mathrm{CO}_{2}$ Yield}

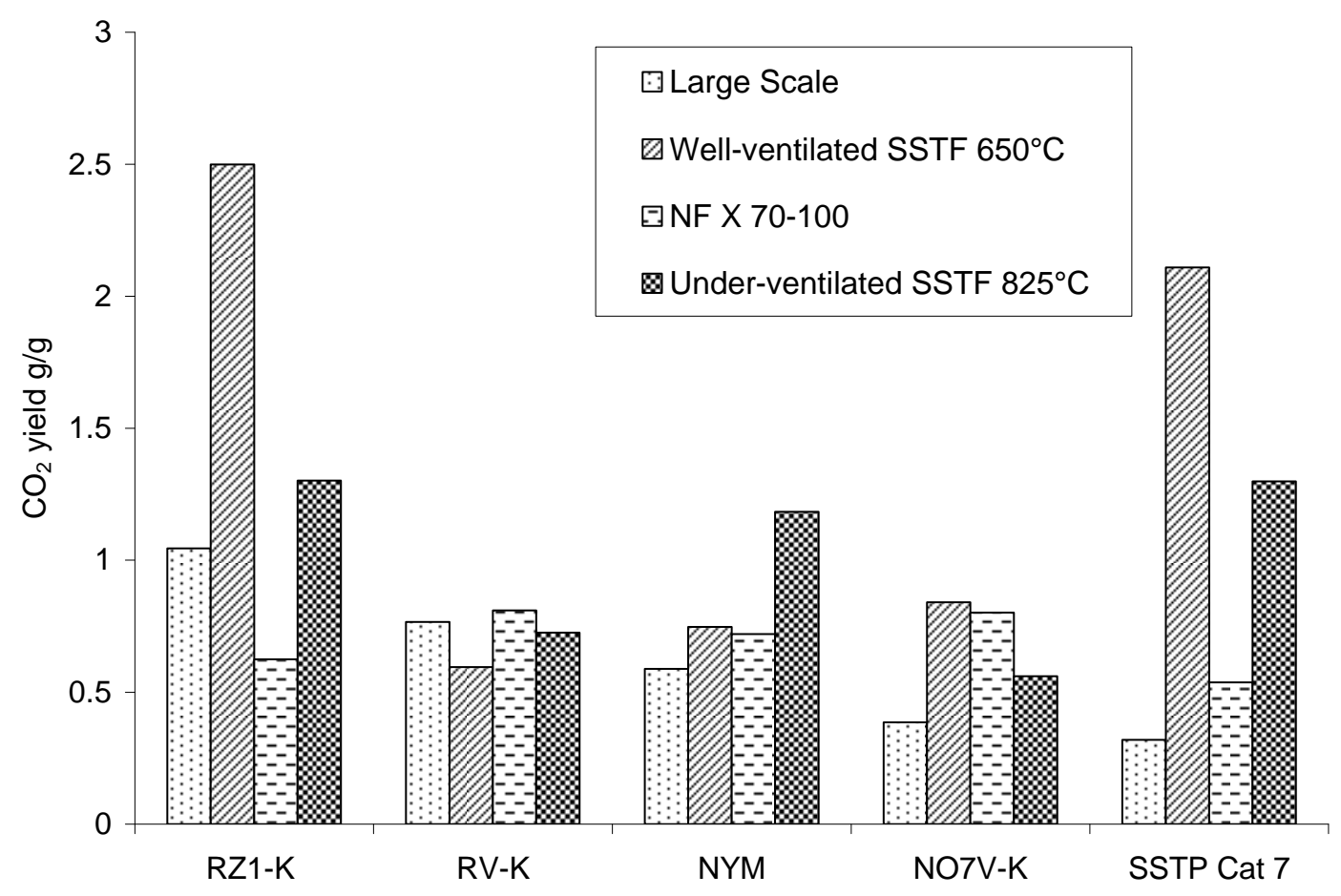

Figure $6 \mathrm{CO}_{2}$ yield on mass loss basis for each of the cables in different fire conditions.

The yield of $\mathrm{CO}_{2}$ indicates the extent of combustion per unit mass of material lost. This depends on a number of factors, including:

- The amount of organic material present in the sample.

- The combustion efficiency (less $\mathrm{CO}$ and hydrocarbons and more $\mathrm{CO}_{2}$ are formed at higher temperatures provided there is sufficient oxygen, and the reactions are not quenched, for example by $\mathrm{Cl}$.).

- The amount of other materials giving rise to mass loss (such as water from a hydrate sheath or $\mathrm{HCl}$ from PVC),

Also, to a lesser extent,

- the evolution of $\mathrm{CO}_{2}$ from chalk decomposition (if present) either thermally, above $750^{\circ} \mathrm{C}$, or by the action of $\mathrm{HCl}$.

Figure 6 shows the $\mathrm{CO}_{2}$ yield on a mass loss basis for each of the cables in different fire conditions. The three halogen containing cables RV-K, NYM and NO7V-K show remarkably good agreement between the different test methods. There is less agreement for the RZ1-K and the SSTP Cat 7 cable in the large scale test and the steady state tube furnace. There are two possible explanations for this. The steady state tube furnace raises the temperature of the whole sample to $650^{\circ} \mathrm{C}$ (or $825^{\circ} \mathrm{C}$ ) during the run. This is sufficient for near complete conversion of $\mathrm{CO}$ and hydrocarbons in the gas phase to $\mathrm{CO}_{2}$. Below a threshold of about $500^{\circ} \mathrm{C}$ the rate of conversion of $\mathrm{CO}$ to $\mathrm{CO}_{2}$ in the gas phase is negligible ${ }^{14}$. In the earlier stages of the large scale test, the fire gases may be quenched in the cool apparatus. Alternatively, within the large scale test (which was designed to measure the extent of vertical flame spread) parts of the cable length may only reach $300-400^{\circ} \mathrm{C}$ (a temperature where hydrated fillers would decompose releasing water and losing mass) but with a high 
proportion of the polymer remaining in the residue. Observation of large scale tests indicates that in many cases only surface burning occurs, leaving most of the cable intact, although on occasions the more flammable inner insulation can drip downwards with burning from the inside out.

\section{CO Yield}

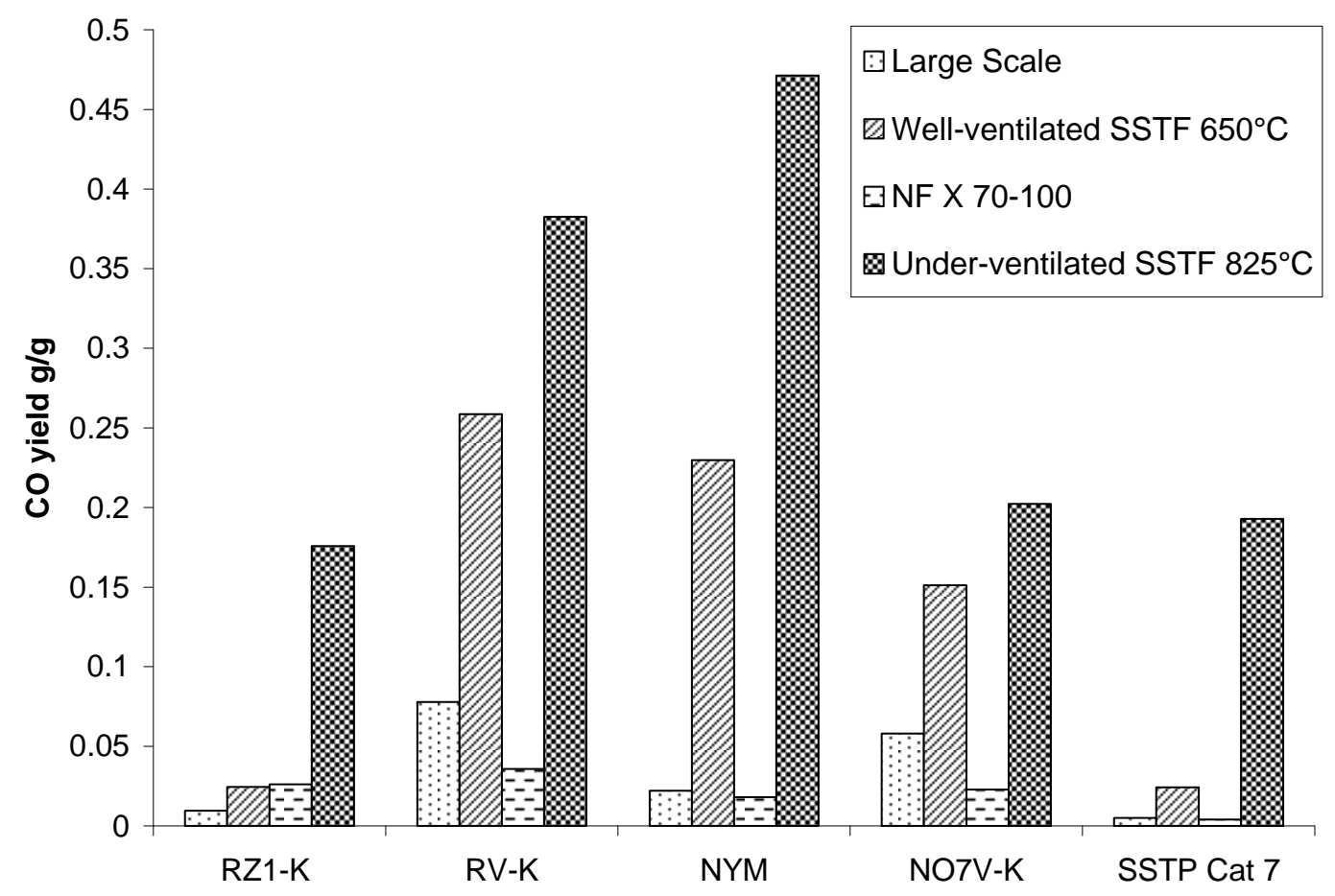

Figure $7 \mathrm{CO}$ yield on mass loss basis for each of the cables in different fire conditions

Figure 7 shows the $\mathrm{CO}$ yield for each of the cables in different fire test conditions. The CO yield is highly dependent on fire condition, as discussed in the introduction. Carbon monoxide is generally assumed to be the main toxicant in fire gases. The data shows a clear trend of higher $\mathrm{CO}$ yields (following the correspondingly lower $\mathrm{CO}_{2}$ yields) for the three halogen-containing cables in all scales, and a general increase in CO yield in progressing from the very well-ventilated large scale fire scenario, the well-ventilated scenario in the steady state tube furnace, the less well-ventilated NF X 70-100 scenario to the underventilated steady state tube furnace condition. Decomposition of hydrated filler, leaving more of the organic material intact, may also have contributed to the lower $\mathrm{CO}$ yields from the large scale test. This is corroborated by the good agreement of the $\mathrm{CO}_{2} / \mathrm{CO}$ ratios. Research predicting the carbon monoxide evolution from flames of simple hydrocarbons ${ }^{14}$, has shown the importance of the equivalence ratio, $\phi$ (Equation 2).

$\begin{array}{llc} & & \text { Typical CO yield } \\ & & \text { g/g } \\ \phi<1 & \text { fuel lean flames } & 0.01 \\ \phi=1 & \text { stoichiometric flames } & 0.05 \\ \phi>1 & \text { fuel rich flames } & 0.2\end{array}$


In a fully developed fire, with low ventilation, $\phi$ can be as large as 5 . For many aliphatic hydrocarbon polymers, CO yield increases rapidly with increase in $\phi$, almost independent of polymer ${ }^{5}$ In other work on the same cables, the CO yield from NYM showed a large variation with equivalence ratio in the steady state tube furnace, giving a high yield of $\mathrm{CO}$ both for very well-ventilated and under-ventilated flaming combustion $(0.58 \mathrm{~g} / \mathrm{g}$ at $\phi=0.125$, falling to $0.15 \mathrm{~g} / \mathrm{g}$ at $\phi=0.5$, then rising to $0.7 \mathrm{~g} / \mathrm{g}$ at $\phi=3.3$ ). Again, this suggests the combination of two quenching mechanisms, one from the halogen, and the other from over-ventilation, operating in the tube furnace when set up for well ventilated burning. There may well be differences between the two NYM cable formulations, which alter the trapping efficiency of the $\mathrm{HCl}$ by the chalk.

\section{Hydrogen chloride yield}

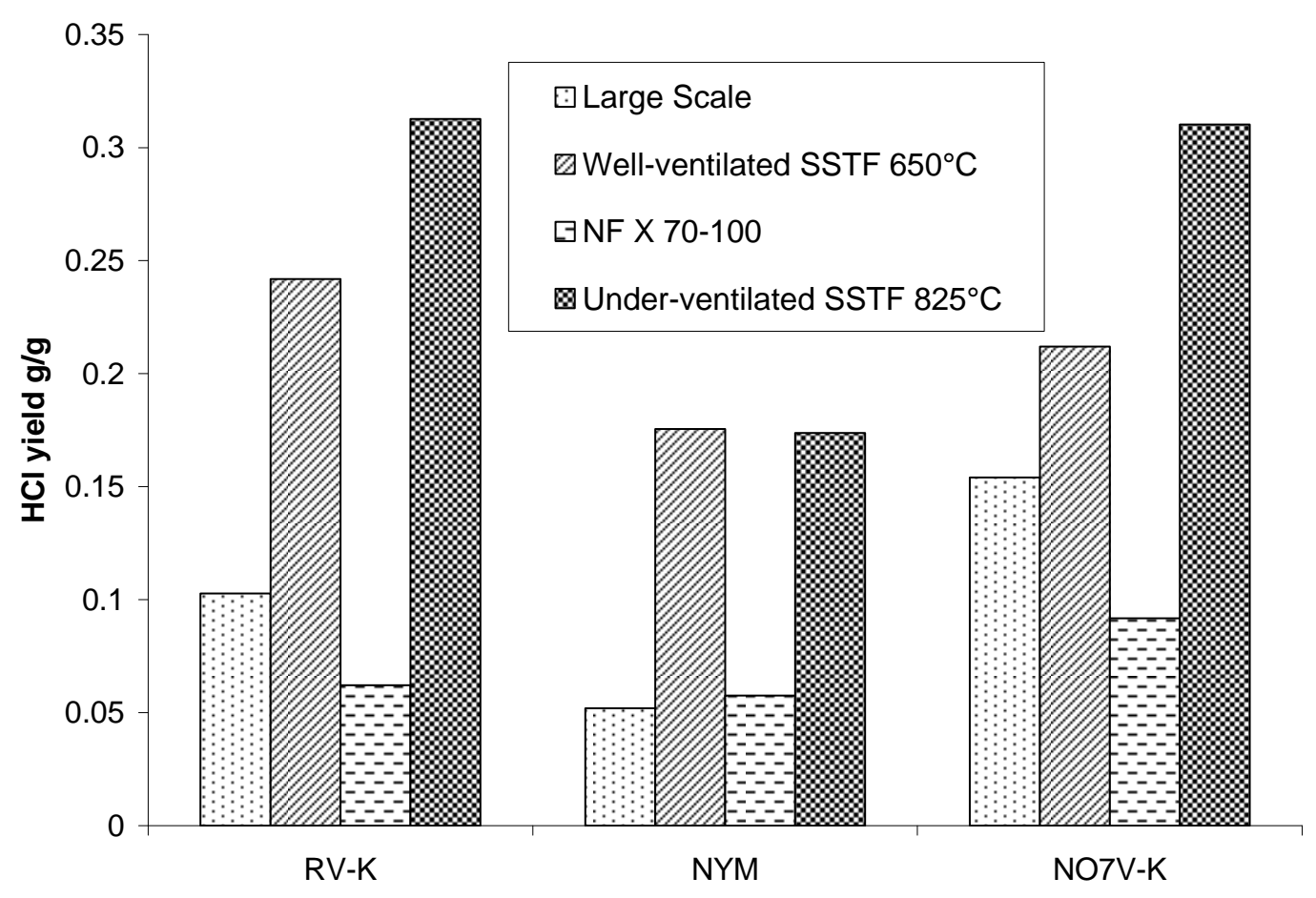

Figure $8 \mathrm{HCl}$ yield on a mass loss basis for the cables containing PVC

Figure 8 shows the yield of $\mathrm{HCl}$ from the steady state tube furnace compared with the static tube furnace and the large scale test, for the three PVC containing cables. The higher yields of $\mathrm{HCl}$ in the steady state tube furnace, which correspond to the amount of $\mathrm{HCl}$ which may be expected to be present in a PVC cable may result from he simpler experimental set-up minimising $\mathrm{HCl}$ loss to the apparatus walls etc. It is also known that $\mathrm{HCl}$ becomes attached to both water droplets and soot particles, which may be deposited on walls and trapped on filters. The 6 metre exhaust duct in the large scale test is likely to allow larger soot particles to form, and for greater accumulation of $\mathrm{HCl}$ on their growing surfaces. In addition, the method of analysis used with the steady state tube furnace, using bubblers to collect soluble material from unfiltered fire effluent, avoids the loss on filters and probably more accurately reflects 
the actual yield of $\mathrm{HCl}$ from the cables. Thus although the large scale test may be expected to show greater $\mathrm{HCl}$ losses than the tube furnaces, in practice the differences may also arise from the sampling technique. The higher $\mathrm{CO}$ yields in the steady state tube furnace, which are highly dependent on the presence of $\mathrm{HCl}$, for $\mathrm{NYM}, \mathrm{RV}-\mathrm{K}$ and NO7V-K may be the result of more efficient mixing in the furnace tube and greater adsorption and deposition of $\mathrm{HCl}$ in the large scale tests.

\section{Smoke yield}

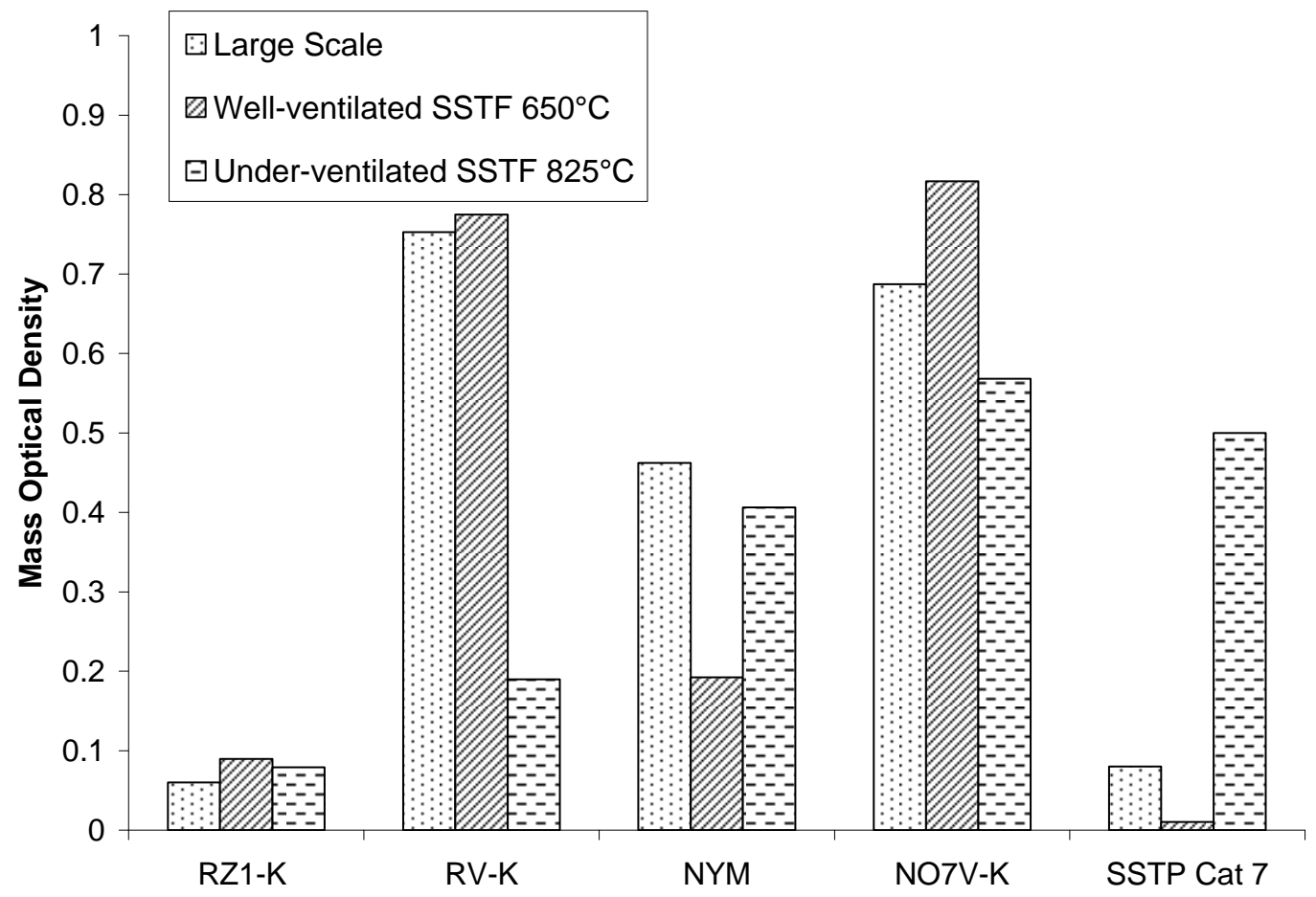

Figure 9 Smoke production from the cables under different conditions, presented as optical density

Figure 9 shows the smoke production for each of the cables under the different fire conditions, expressed as mass optical density ${ }^{15}$, per unit mass of material burnt. Again this shows fairly good agreement between the scales, despite the difficulties of scale-up for smoke production. It also confirms the expectation that gas phase (e.g. halogen) fire retardants tend to produce much more soot in their fire effluents through the production of polyaromatic soot precursors and interfering with gas phase combustion reactions. However, the anomalous result for RV-K at $825^{\circ} \mathrm{C}$ in the SSTF suggests that combustion of aromatic soot precursors may occur more readily at higher temperatures, even under oxygen depleted conditions.

\section{Estimation of fire effluent toxicity}

During a real fire, the concentration of the various toxic products vary with time. Calculation of the toxic hazard of fire gases from a real fire requires assumptions about these variations, especially for less fully-developed non-steady state fires which are generally less severe, such as the large scale fire test considered here. Further, the fire effluent will be diluted before its toxicity is assessed (ISO 13344 recommends 
that enough oxygen should be present to avoid hypoxia being the major hazard ${ }^{11}$ ). The gas concentrations from each experiment have been normalised to the effluent from $1 \mathrm{~g}$ of material loss in 50 litres of air. The total mass of each gas was converted to ppm using a nominal volume of 50000 litres, the volume of undiluted fire gases passed through the large scale apparatus in just over 6 minutes. This figure was chosen because each of the five cables had undergone most of their heat release in around 6 minutes. The oxygen concentrations (for the hypoxia component of FED) for the large scale were estimated from the minimum oxygen concentrations during the test.

In the steady state tube furnace the organic species in the fire effluent (measured as the difference in $\mathrm{CO}_{2}$ before and after passing over the secondary oxidiser) were assessed by taking a collective yield of $10 \mathrm{mg} \mathrm{litre}^{-1}$ to result in incapacitation, as described by Purser ${ }^{16}$. In the large scale test, two of the major irritant gases, acrolein and formaldehyde were analysed individually and their contribution to the FED is shown as "organics".

The individual contributions of each gas to the FED are shown in Figure 10.

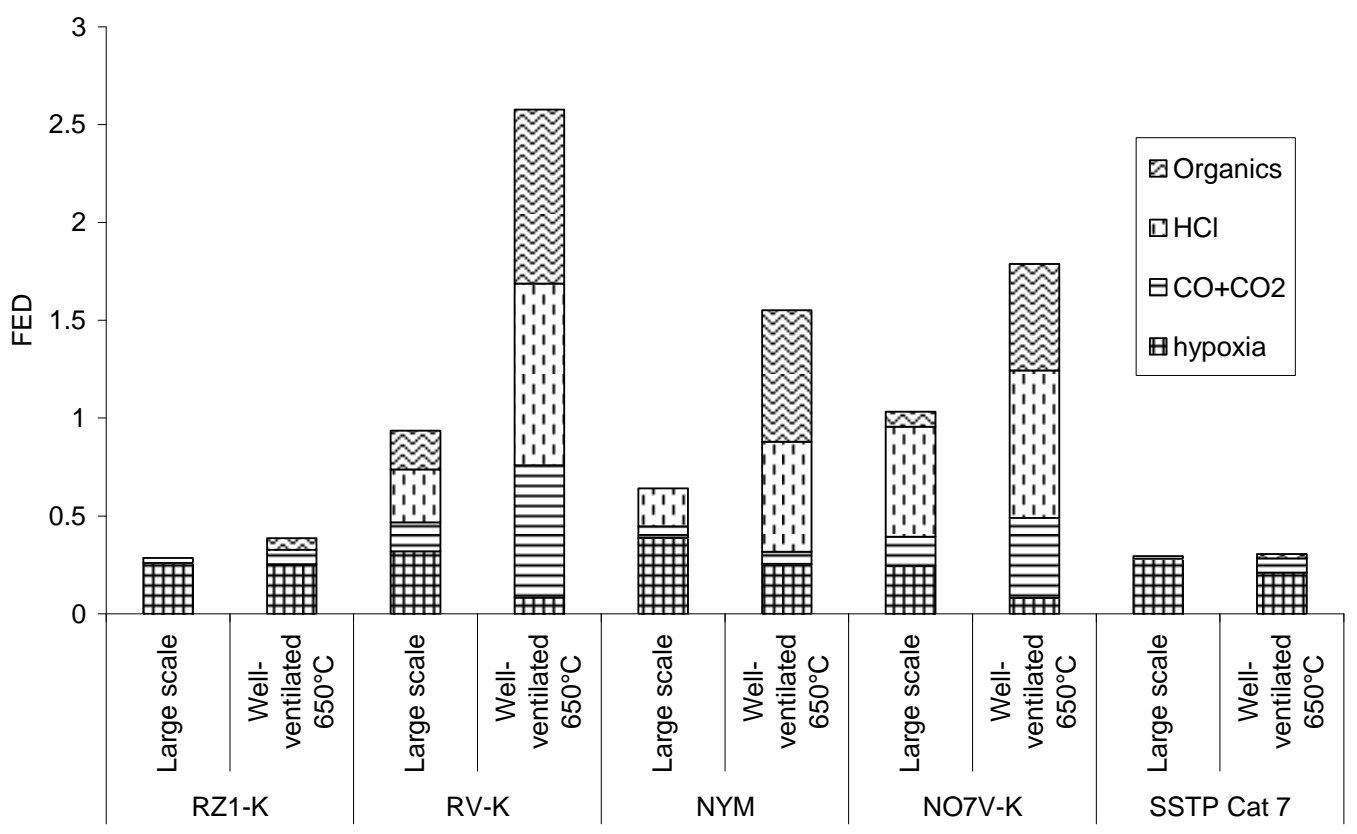

Figure 10 Fractional Effective Dose (FED) of fire effluents from bench- and large-scale tests

This shows good agreement between the two methods, and comparable contributions from each component, within the limitations of the data available. It also predicts significantly greater fire gas toxicity from burning the same mass of halogen containing cable (RV-K, NYM and NO7V-K) than from burning either of the zerohalogen formulations.

The mass loss data for the large scale test shows differences in the extent of burning for the different cables, which would impact on the assessment of toxic hazard. While it is outside the scope of this work, and clearly highly dependent on the fire scenario, (including details such as the mounting and separation of the cables) simply 
multiplying the FED by extent of burning (the ratio of the mass lost in the large scale test to the tube furnace) gives an indication of the relative toxic hazard for the particular fire scenario represented by the prEN 50399-2-2 test. This data is shown in Figure 11.

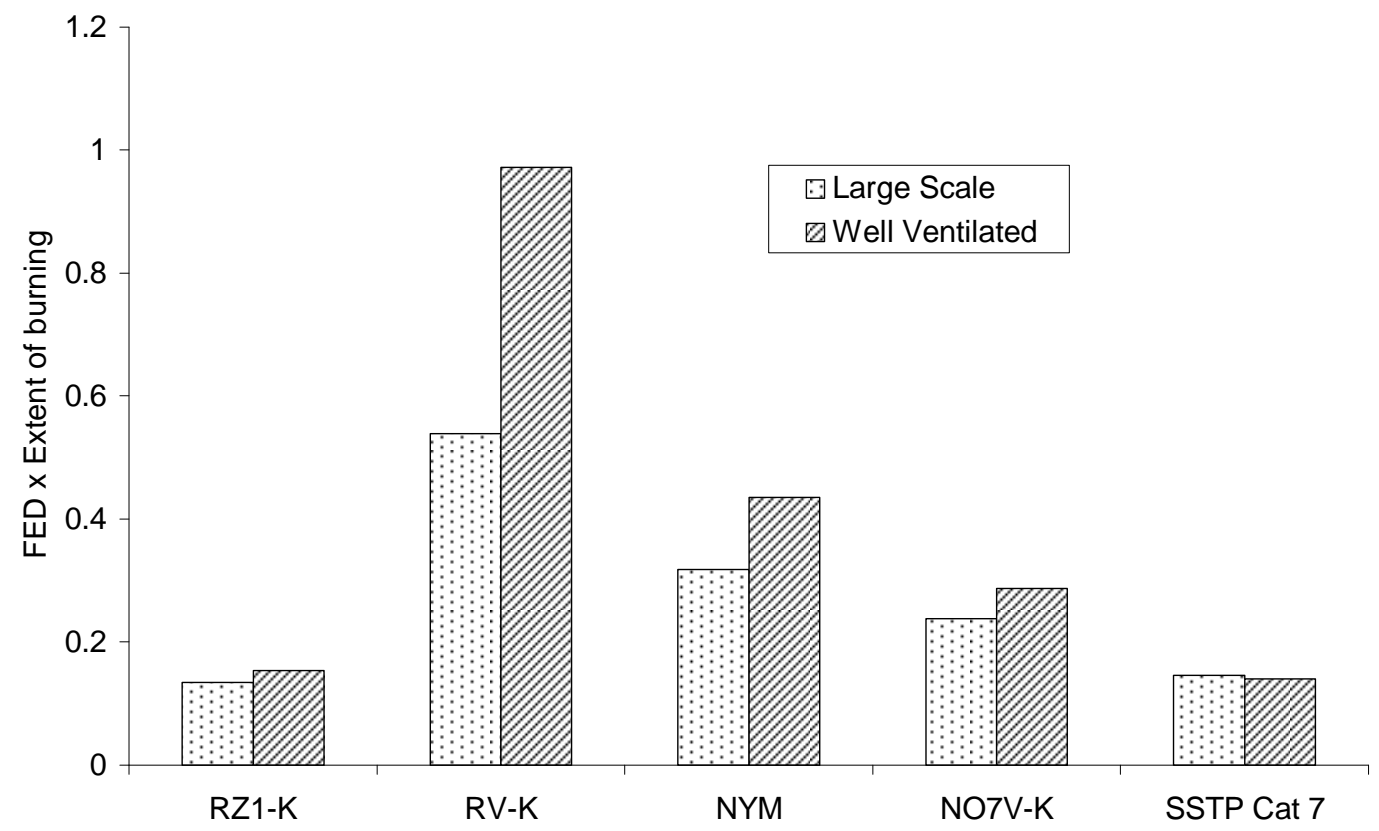

Figure 11 Simplified relative toxic hazard assessment, obtained by multiplying the toxic product yields and the extent of burning from the large scale test.

For the three energy cables, of broadly similar construction, this shows the greatest relative toxic hazard in this particular fire scenario would come from the RV-K cable, followed by the NYM cables, with the lowest toxic hazard coming from the zerohalogen cable. For the much thinner NO7V-K a comparison is invalid because of the different burning behaviour. In this case a small triangle of cable burns so rapidly that the remaining cable does not ignite, leaving most of the cable undamaged. This illustrates that, for the cables considered here, the differences between the bench and large scale test data become almost insignificant compared to the differences between materials and fire scenarios, when used as part of a toxic fire hazard assessment. 


\section{Conclusions}

Few, if any, attempts have been made to relate the toxic product yields from burning cables from large scale fires with bench scale physical fire models. This is difficult because of the complex construction and burning behaviour of cables (often having a fire retarded sheath surrounding more flammable insulation) and the variability inherent in large scale fires. However, it is worthwhile, as this work shows, because meaningful conclusions on the toxicity of the large scale fire effluent can be drawn from the bench scale data. In order to obtain meaningful comparisons, several factors must be taken into account. These include

- $\quad$ the fire condition (particularly temperature and ventilation);

- the extent of burning;

- the fate of any (inorganic) residue

- the physical form of the fuel (such as the axial inhomogeneity of electric cables and the geometry and orientation of their mounting).

This work shows that the data from the different scales does show reasonable correspondence, once these factors have been dealt with.

The results show clearly that the whole cable approach used in the steady state tube furnace is more appropriate to predicting the toxic product yield in large scale fires than the weighted average of the individual components of the NFX-70-100 test. For example, $\mathrm{HCl}$ will affect the combustion efficiency of all the components in a burning cable, not just the PVC, so they must all be burnt together.

The steady state tube furnace allows more complete mixing of the gases within the fire plume (as they travel down the heated tube) than occurs in the large scale test (where, at least in the initial stages, the fire plume will be quenched by the cooler air in the large volume of the cabinet). Thus the steady state tube furnace replicates an essentially static system, where the large scale test, or a real fire represents a dynamic system. Several tube furnace experiments may be required to cover the most significant stages of a particular fire. However, as the scale of an enclosure fire increases, so quasi-steady state conditions will prevail, as the fire becomes ventilation controlled and a plateau is observed in the heat release curve. This is seen in the increased inhibition by $\mathrm{HCl}$ on the conversion of $\mathrm{CO}$ to $\mathrm{CO}_{2}$. The large scale cable burns reported here only lasted for around 6 minutes, before more complete heating, and hence mixing of the fire plume occurred. Higher CO yields from PVC based materials may be expected from the earlier stages of a typical cable fire. As the fire scenario develops towards underventilation, the CO yield from all the cables would be expected to increase.

Although the data from the different scales does not correlate perfectly, there is significant differentiation between different cable types, and some general trends emerge. It is clear that only a portion of the cables burn in the large scale test, and that significant uneven decomposition occurs, particularly to the hydrate sheaths. The fire stage of the large scale test appears to have been replicated in an appropriate manner, given the correspondence of the $\mathrm{CO}_{2} / \mathrm{CO}$ ratios. The yields of $\mathrm{CO}_{2}, \mathrm{CO}, \mathrm{HCl}$ and smoke show reasonable agreement, given the differences in extent of burning, and the problems of quantifying it. When these are translated into estimates of the toxicity of the fire gases (the FED values), the significance of the different 
components becomes more apparent, though reasonable agreement is maintained between the two scales, particularly for the more toxicologically significant components of the fire effluent.

The tube furnace burns the cable completely, as may be the case in an unwanted fire, and hence the data obtained does not take into account the flammability of the cable. The hazard data from the large scale test is a complex mixture of flammability and toxic product yields, which may be very different in a different fire scenario. These have been combined to demonstrate the estimation of toxic hazard for a particular fire scenario based around the large scale test. This shows only marginal sensitivity to the differences in toxic product yield between the tube furnace and the large scale test, suggesting that using the extent of burning data from a suitable fire scenario with toxic product yields from the IEC 606095-7-50 apparatus (Purser furnace) could produce data required for toxic hazard assessment from burning cables.

\section{Acknowledgements}

One of us (KL) would like to thank the European Association of Producers of Flame Retarded Olefinic Cable Compounds (FROCC) for the provision of a project studentship to support this work. 


\section{References}

1 Fire Statistics United Kingdom 2002, Office of the Deputy Prime Minister: London, April 2004.

2 T R Hull, R E Quinn, I G Areri and D A Purser, Polymer Degradation and Stability, 77, 235-242 (2002).

3 ISO TS 13571:2001 Life threat from fires - Guidance on the estimation of time available for escape using fire data

$4 \quad$ ISO TS 19706:2004, Guidelines for assessing the fire threat to people.

5 T R Hull, J M Carman, and D A Purser, Polymer International, 1259-1265, 49, (2000).

6 T R Hull and K T Paul, Fire Safety Journal 42, XXX, (2007) [in press]

7 IEC 60695-7-50:2002 Fire hazard testing - Toxicity of fire effluent - Estimation of toxic potency - Apparatus and test method. International Electrotechnics Commission, Geneva.

8 M M Hischler in Fire and Polymers: Materials and Solutions for Hazard Prevention, Ed. G L Nelson and C A Wilkie, ACS Symposium series No. 797, 293-306 (2001).

9 Y Alarie, Critical Reviews in Toxicology, 32, 259-289, (2002)

10 P Andersson, L Rosell, M Simonson, and V Emanuelsson, Fire Technology, 40, 247262, (2004)

11 ISO 13344:1996 (Estimation of lethal toxic potency of fire effluents).

12 T R Hull, C L Wills, T Artingstall, D Price and G J Milnes, in Fire Retardancy of Polymers, Edited by Bourbigot S. LeBras M, and Wilkie C.A., Chapter 28, p372 Royal Society of Chemistry, (2005)

13 A Schnipper, L Smith-Hansen, S E Thomsen, Fire and Materials, 19, 61-64, (1995).

14 W M Pitts, Progress in Energy and Combustion Science, 21, p.197-237 (1995)

15 D Drysdale, An Introduction to Fire Dynamics, 2nd Edition, pub. John Wiley and Sons Ltd, England, 1998.

16 D A Purser, Toxicity Assessment of Combustion Products in SFPE Handbook of Fire Protection Engineering 3rd Edition 2-117 (2002). 